\title{
Structural and Optical Properties of Zinc Borotellurite Glass Co-Doped with Lanthanum and Silver Oxide
}

\author{
Faznny Mohd Fudzi ${ }^{1}$, Halimah Mohamed Kamari1 ${ }^{*}$, Farah Diana Muhammad ${ }^{2}$, \\ Amirah Abd Latif ${ }^{2}$, Zaitizila Ismail ${ }^{1}$ \\ ${ }^{1}$ Glass and Dielectric Lab, Physics Department, Faculty of Science, Universiti Putra Malaysia, Serdang, Malaysia \\ ${ }^{2}$ Photonic Lab, Physics Department, Faculty of Science, Universiti Putra Malaysia, Serdang, Malaysia \\ Email: faznnymf@gmail.com, *halimahmk@upm.edu.my, farahdia na@upm.edu.my, amirahlati@upm.edu.my, \\ zaitizila@yahoo.com
}

How to cite this paper: Fudzi, F.M., Kamari, H.M., Muhammad, F.D., Latif, A.A. and Ismail, Z. (2018) Structural and Optical Properties of Zinc Borotellurite Glass CoDoped with Lanthanum and Silver Oxide. Journal of Materials Science and Chemical Engineering, 6, 18-23.

https://doi.org/10.4236/msce.2018.64003

Received: March 8, 2018

Accepted: April 5, 2018

Published: April 12, 2018

\begin{abstract}
A series of zinc borotellurite glass co-doped with lanthanum and silver oxide with the chemical formula of

$\left[\left\{\left[\left(\mathrm{TeO}_{2}\right) 0.7\left(\mathrm{~B}_{2} \mathrm{O}_{3}\right)_{0.3}\right]_{0.7}(\mathrm{ZnO})_{0.3}\right\}_{0.96}\left(\mathrm{La}_{2} \mathrm{O}_{3}\right)_{0.04}\right]_{1-\mathrm{x}}\left(\mathrm{Ag}_{2} \mathrm{O}\right)_{\mathrm{x}}$ where the molar fraction of silver oxide, $\mathrm{x}=0.02,0.04,0.06,0.08$ and 0.10 had been successfully prepared via the conventional melt-quenching technique. The structural properties of the glasses were unveiled through X-ray Diffraction (XRD) and Fourier Transform Infra-Red (FTIR) spectroscopy while optical properties of the glasses were investigated with Ultra Violet Visible (UV-Vis) spectrophotoscopy. The short range periodic atomic arrangement in the glass matrix that implies the amorphous nature of the glass was confirmed with the presence of a broad hump in the XRD pattern. On the other hand, the three absorption bands observable in the FTIR spectra had proven the existence of $\mathrm{BO}_{4}, \mathrm{BO}_{3}$ as well as $\mathrm{TeO}_{4}$ units in the glass network. The absorbance values retrieved from UV-Vis spectroscopy were utilized to calculate the indirect energy band gap and Urbach energy values of the fabricated glass. By employing the equations proposed by Mott and Davis, the obtained indirect energy band gap have values ranging from 2.16 to $4.16 \mathrm{eV}$.The decreasing trend in indirect energy band gap and increasing Urbach energy values were related to the increasing number of nonbridging oxygen (NBO) in the glass that is created from the breaking of Te-O-Te or B-O-B bonds after lanthanum as well as silver oxide are incorporated into the zinc borotellurite glass network.
\end{abstract}

\section{Keywords}

Zinc Borotellurite Glass, Lanthanum Oxide, Silver Oxide, Optical Band Gap, 
Urbach Energy

\section{Introduction}

Recently, rare earth doped glass has been attracting the attention of many researchers due to its potential to be utilized as optical fibers, waveguide lasers, bulk laser, optical amplifiers and infrared active optical devices [1]. In this research, tellurite was chosen to be one of the glass former because of its low melting point, low crystallizability, good chemical durability, high thermal stability, high linear as well as nonlinear refractive index and significant rare earth ion solubility [2] [3] [4]. Since tellurite oxide is a conditional glass former that requires the addition of other glass former oxide or transition metal oxide in order to form a glass, a well-known glass former oxide, borate oxide was introduced into the tellurite glass to increase the glass forming ability of the overall glass system. The incorporation of zinc oxide should help in improving the glass forming ability and reducing the crystallization rates in a borotellurite glass matrix [3] while the addition of silver oxide will usually leads to the enhancement in the optical properties of a glass network. Based on the previous research done by Faznny et al. [5], the addition of lanthanum oxide into zinc borotellurite glass seems toincrease the energy band gap and reduce the Urbach energy of the glass system. Thus, through this study, the effect of silver oxide to the optical properties of lanthanum zinc borotellurite glass network will be determined and discussed.

\section{Methodology}

$\mathrm{La}^{3+}$ and $\mathrm{Ag}^{+}$co-doped zinc borotellurite glasses were prepared via melt quenching technique by using reagent grade chemical powders of tellurium oxide $\left(\mathrm{TeO}_{4}\right)$, boron oxide $\left(\mathrm{B}_{2} \mathrm{O}_{3}\right)$, zinc oxide $(\mathrm{ZnO})$, lanthanum oxide $\left(\mathrm{La}_{2} \mathrm{O}_{3}\right)$ and silver oxide $\left(\mathrm{Ag}_{2} \mathrm{O}\right)$ with the purity of $99.99 \%$ from Alfa Aesar as starting materials. All the chemicals were weighted by using a digital weighing balance with an uncertainty of $\pm 0.0001 \mathrm{~g}$. The chemical mixture was put into alumina crucible and mixed for 30 minutes before being transferred into the first electrical furnace for preheating process. The preheating process was done at $400^{\circ} \mathrm{C}$ for a period of one hour to remove any water vapor in the chemical powders. The alumina crucible containing preheated chemical mixture was transferred to second electrical furnace in order to allow melting process to take place at $900^{\circ} \mathrm{C}$ for two hours. After two hours, the molten chemical mixture was quickly quenched into a preheated cylinder mould and sent to the first furnace to be annealed at $400^{\circ} \mathrm{C}$. The first furnace was switched off after one hour whereby the glass was left to cool to room temperature overnight in the furnace. Part of the prepared glass was polished both side to procure flat and parallel surface for optical characterization while the remaining glass sample was crushed and 
grinded to acquire powder form glass sample for structural characterization.

\section{Result and Discussion}

\subsection{X-Ray Diffraction (XRD) Spectroscopy}

XRD is a non-destructive testing method that has been employed to detect the presence of any crystalline phase in a material via the diffraction and the scattering of X-ray as it pass through the material [6]. The XRD pattern from the powder form glass samples that were documented at $2 \theta$ angles in the range of $20^{\circ}$ to $80^{\circ}$ under room temperature are illustrated in Figure 1. The absence of sharp peak proven that there are no crystalline phase exist in the samples. Broad hump that is observable in the XRD pattern suggests that the fabricated glass sample is composed of glassy phase and is amorphous in nature [7].

\subsection{Fourier Transform Infra-Red (FTIR) Spectroscopy}

The crucial information on the arrangement of the structural units of a glass material can be revealed with the help of FTIR spectroscopy [8]. The powder form glass samples were characterized under room temperature in the wave number ranging from 200 to $1800 \mathrm{~cm}^{-1}$ in order to obtain the FTIR spectra as depicted in Figure 2. The absorption bands recorded in the range of 655.8 to $667.4 \mathrm{~cm}^{-1}$ as well as 933.6 to $952.8 \mathrm{~cm}^{-1}$ are assigned to the trigonalbipyramid $\mathrm{TeO}_{4}$ units and tetrahedral $\mathrm{BO}_{4}$ units respectively which represent the existence of bridging oxygen (BO) in the glass matrix [9] [10]. In contrast, a shoulder observable at the range between 1330.9 and $1350.2 \mathrm{~cm}^{-1}$ has proven the formation of non bridging oxygen (NBO) in the zinc borotellurite glass system [11].

\subsection{Ultra Violet Visible (UV-Vis) Spectrophotometer}

Optical absorption data acquired from the UV-Vis spectrophotometer are essential for the inspection of the optically induced transition as well as the determination of the optical energy band gap [12]. Indirect energy band gap from indirect transition that usually occurred in vitreous materials like glass when electrons are excited to the conduction band from the valence band can be calculated via the relation proposed by Mott and Davis as below;

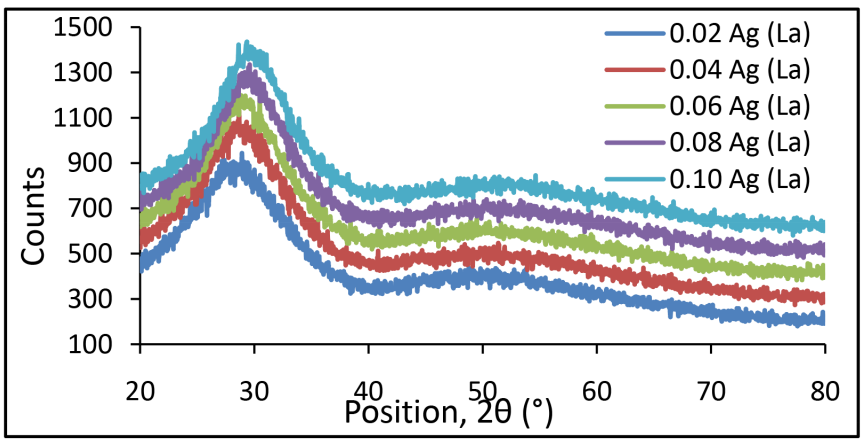

Figure 1. XRD pattern for zinc borotellurite glass co-doped with lanthanum and silver oxide. 


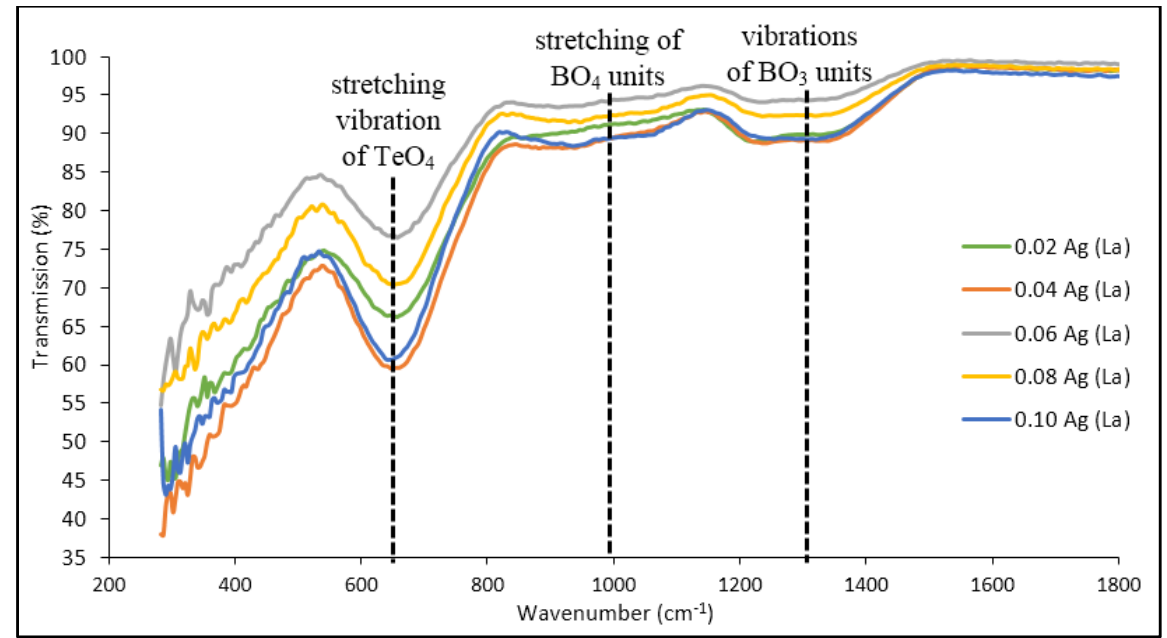

Figure 2. FTIR spectra for zinc borotellurite glass co-doped with lanthanum and silver oxide.

$$
\alpha h w^{1 / 2}=B\left(h w-E_{o p t}\right)
$$

where $\alpha$ is the absorption coefficient, $\hbar w$ represents the photon energy, $\mathrm{B}$ is a constant called band tailing parameter and Eopt stands for the indirect energy band gap. Meanwhile, Urbach energy that able to provide the information on the disorderness in the glass network can be computed by using Equation (2) [13];

$$
\alpha(w)=B \exp \left(\frac{\hbar w}{\Delta E}\right)
$$

where $\alpha(w)$ is the absorption coefficient, $\hbar \mathrm{w}$ is the the photon energy, $\mathrm{B}$ represents a constant and $\Delta \mathrm{E}$ stands for the Urbach energy. Figure 3 and Figure 4 show the indirect energy band gap and Urbach energy of the prepared glass whereby indirect energy band gap decreases remarkably while Urbach energy increases drastically as more silver oxide are incorporated into the glass system. Structural changes and the formation NBO in the glass system as silver oxide concentration increases have resulted in the intense decrement of the indirect energy band gap values [14]. The large and increasing Urbach energy values of thezinc borotellurite glass co-doped with lanthanum and silver oxideindicate that the fabricated glass has a glassy nature and great inclination to convert weak bonds into defects [15] [16]. As the amount of silver oxide in the glass increases, the Urbach energy of the prepared glass also increases because of the formation of bonding defects that create more NBO in the glass network.

\section{Conclusion}

The effect of the inclusion of different concentration of silver oxide in lanthanum zinc borotellurite glass is unveiled and discussed in this work. The glassy nature of the prepared glass has been proven by the presence of broad hump in the XRD pattern. In general, it can be said that the optical properties of the lanthanum zinc borotellurite glass has been enhanced with the addition of silver oxide in the glass matrix. The decreasing indirect energy band gap and 


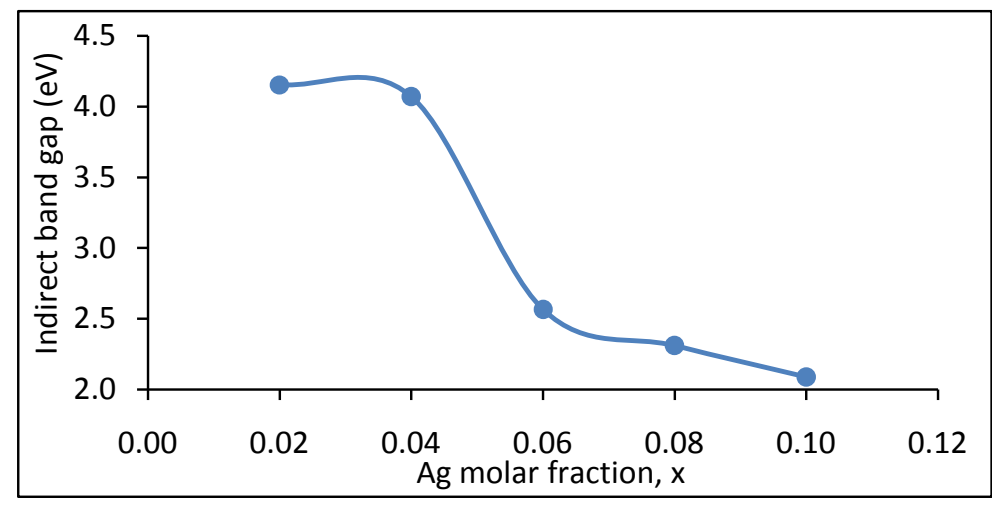

Figure 3. Indirect energy band gap of zinc borotellurite glass co-doped with lanthanum and silver oxide.

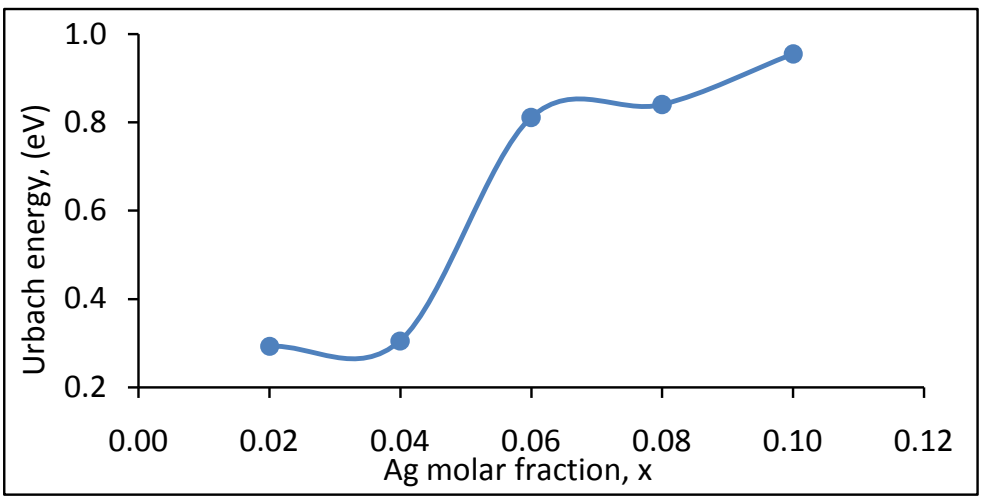

Figure 4. Urbach energy of zinc borotellurite glass co-doped with lanthanum and silver oxide

increment in Urbach energy indicate that the incorporation of silver oxide in the glass system will contribute to the breaking of weak bond as well as the formation of NBO. The creation of NBO as a result of the breaking of B-O-B as well as $\mathrm{Te}$-O-Te bond can be verified through the presence of $\mathrm{TeO}_{4}, \mathrm{BO}_{4}$ and $\mathrm{BO}_{3}$ in the FTIR spectra.

\section{Acknowledgements}

The authors are thankful for the financial support from Universiti Putra Malaysia (UPM) through GP-IPS (grant number: 9490000).

\section{References}

[1] Lin, H., Yang, D., Liu, G., Ma, T., Zhai, B., An, Q., Yu, J., Wang, X., Liu, X. and Pun, E.Y.B. (2005) Optical Absorption and Photoluminescence in $\mathrm{Sm}^{3+}$ - and $\mathrm{Eu}^{3+}$-Doped Rare-Earth Borate Glasses. J. Lumin, 113, 121-128.

https://doi.org/10.1016/j.jlumin.2004.09.115

[2] Safonov, V.V. (2007) Synthesis and Properties of Molybdenum Tellurite Glasses of the $\mathrm{BaCl}_{2}-\mathrm{MoO}_{3}-\mathrm{TeO}_{2}$ System. Russian Journal of Inorganic Chemistry, 52, 326-328. https://doi.org/10.1134/S0036023607030059

[3] Dousti, M.R. and Hosseinian, S.R. (2014) Enhanced Upconversion Emission of 
Dy $^{3+}$-Doped Tellurite Glass by Heat-Treated Silver Nanoparticles. J. Lumin, 154, 218-223. https://doi.org/10.1016/j.jlumin.2014.04.028

[4] Mahraz, Z.A.S., Sahar, M.R., Ghoshal, S.K. and Dousti, M.R. (2013) Concentration Dependent Luminescence Quenching of $\mathrm{Er}^{3+}$-Doped Zinc Boro-Tellurite Glass. J. Lumin, 144, 139-145. https://doi.org/10.1016/j.jlumin.2013.06.050

[5] Faznny, M.F., Halimah, M.K. and Azlan, M.N. (2016) Effect of Lanthanum Oxide on Optical Properties of Zinc Borotellurite Glass System. Journal of Optoelectronics and Biomedical Materials, 8, 49-59.

[6] Usman, A., Halimah, M.K., Latif, A.A., Muhammad, F.D. and Abubakar, A.I. (2018) Influence of $\mathrm{Ho}^{3+}$ Ions on Structural and Optical Properties of Zinc Borotellurite Glass System. J. Non-Cryst. Solids, 483, 18-25.

https://doi.org/10.1016/j.jnoncrysol.2017.12.040

[7] Jambhale, V.N. and Chanshetti, U.B. (2018) Synthesis and Characterization of Boro-Aluminotellurite Glass System. Journal of Chemistry and Chemical Sciences, 8 , 199-203.

[8] Farouk, M., Samir, A. and El Okr, M. (2018) Effect of Alkaline Earth Modifier on the Optical and Structural Properties of $\mathrm{Cu}^{2+}$ Doped Phosphate Glasses as a Bandpass Filter. Physica B, 530, 43-48. https://doi.org/10.1016/j.physb.2017.11.013

[9] Ersundu, M.C. and Ersundu, A.E. (2016) Structure and Crystallization Kinetics of Lithium Tellurite Glasses. J. Non-Cryst. Solids, 453, 150-157.

https://doi.org/10.1016/j.jnoncrysol.2016.10.007

[10] Terczyńska-Madej, A., Cholewa-Kowalska, K. and Łączka, M. (2011) Coordination and Valence State of Transition Metal Ions in Alkali-Borate Glasses. Opt. Mater, 33, 1984-1988. https://doi.org/10.1016/j.optmat.2011.03.046

[11] Ticha, H., Kincl, M. and Tichy, L. (2013) Some Structural and Optical Properties of $\left(\mathrm{Bi}_{2} \mathrm{O}_{3}\right)_{\mathrm{x}}(\mathrm{ZnO})_{60-\mathrm{x}}\left(\mathrm{B}_{2} \mathrm{O}_{3}\right)_{40}$ Glasses. Mater. Chem. Phys., 138, 633-639.

https://doi.org/10.1016/j.matchemphys.2012.12.032

[12] Oueslati-Omrani, R., Hamzaoui, A.H., Chtourou, R. and M'nif, A. (2018) Structural, Thermal and Optical Properties of Phosphate Glasses Doped with $\mathrm{SiO}_{2}$. J. Non-Cryst. Solids, 481, 10-16. https://doi.org/10.1016/j.jnoncrysol.2017.08.019

[13] Mohd Fudzi, F., Mohamed Kamari, H., Abd Latif, A. and Muhammad Noorazlan, A. (2017) Linear Optical Properties of Zinc Borotellurite Glass Doped with Lanthanum Oxide Nanoparticles for Optoelectronic and Photonic Application. J. Nanomater, 2017, 1-8.

[14] Hazlin, A., Halimah, M.K., Mohammad, F.D., Faznny, M.F. and Iskandar, S.M. (2017) Effect of Dysprosium Nanoparticles on the Optical Properties of Zinc Borotellurite Glass Systems. Solid State Phenomena, 268, 13-17. https://doi.org/10.4028/www.scientific.net/SSP.268.13

[15] Dalal, S., Khasa, S., Dahiya, M.S., Yadav, A., Agarwal, A. and Dahiya, S. (2015) Optical and Thermal Investigations on Vanadyl Doped Zinc Lithium Borate Glasses. Journal of Asian Ceramic Societies, 3, 234-239. https://doi.org/10.1016/j.jascer.2015.03.004

[16] Mhareb, M.H.A., Hashim, S., Ghoshal, S.K., Alajerami, Y.S.M., Bqoor, M.J., Hamdan, A.I., Saleh, M.A. and Karim, M.A. (2016) Effect of $\mathrm{Dy}_{2} \mathrm{O}_{3}$ Impurities on the Physical, Optical and Thermoluminescence Properties of Lithium Borate Glass. J. Lumin., 177, 366-372. https://doi.org/10.1016/j.jlumin.2016.05.002 